\title{
Painful Hip Arthroplasty: What Should We Find? Diagnostic Approach and Results
}

\author{
Roger Erivan, MD ${ }^{\mathrm{a}, *}$, Guillaume Villatte, MD ${ }^{\text {a }}$, Matthieu Ollivier, MD ${ }^{\mathrm{b}, \mathrm{c}}$, \\ Wayne G. Paprosky, MD ${ }^{\mathrm{d}}$ \\ ${ }^{a}$ Université Clermont Auvergne, CHU Clermont-Ferrand, CNRS, SIGMA Clermont, ICCF, Clermont-Ferrand, France \\ ${ }^{\mathrm{b}}$ Aix-Marseille Université, CNRS, ISM UMR 7287, Marseille, France \\ ${ }^{\mathrm{c}}$ Department of Orthopedics and Traumatology, Institute for locomotion, St. Marguerite Hospital, Marseille, France \\ ' Midwest Orthopaedics at Rush, Central Dupage Hospital, Chicago, IL
}

Keywords:

painful prosthesis

hip arthroplasty

hip pain

total hip arthroplasty

hip revision

\begin{abstract}
A B S T R A C T
Introduction: Identifying the source of pain is paramount for determining appropriate treatment and ensuring successful outcome in terms of management and relief of pain. The difficulty is that each surgeon has his or her own way of seeing the problem, and there is no consensus for the evaluation of these patients. The study hypothesis was that it is possible to find the cause of the pain in most cases.

Patients and methods: All patients consulting for unexplained painful hip arthroplasty were included and followed a decision tree to assess the cause of the pain. The primary endpoint was the final diagnosis. Secondary endpoints were subgroup comparison between main causes and assessment of risk factors. Results: Two hundred one hips of 194 patients were included as unexplained painful hip arthroplasty 6 months postoperatively. Final diagnoses comprised periarticular pain in 53 cases (26.4\%): 40 cases of trochanteric bursitis, 5 of iliopsoas tendinitis, 5 of abductor deficiency, 1 of ischial tuberosity tendinitis, and 2 of heterotopic ossification; projected pain in 49 (24.4\%): 45 cases of back pain with or without neuropathy, 3 of knee osteoarthritis, and 1 of metabolic neuropathy; wear in 40 (19.9\%), in the polyethylene liner; loosening in 20 (10.0\%): loosening of the femoral component in 8 and that of the cup in 12; material problems in 17 (8.5\%): trunnionosis in 13 and metallosis in metal-on-metal implants in 4; no diagnosis in 7 hips (3.5\%); infection in 6 (3.0\%), all chronic; instability without real dislocation in $3(1.5 \%)$; misplacement in 3 (1.5\%), all for leg-length discrepancy; fracture in 2 (1.0\%): 1 of greater trochanter and 1 of ilio-ischiopubic ramus; complex regional pain syndrome in $1(0.5 \%)$.

Discussion: To our knowledge, this is the first study on the causes of painful hip arthroplasty in clinical practice, whether leading to revision or not. A systematic approach, including physical examination, radiographic assessment and laboratory studies, is needed to find the cause of the pain. It is important to understand the pain so that it can be treated appropriately. Revision surgery can sometimes help-but the worst thing is to make the patient worse. Level of Evidence: level 4, retrospective study.
\end{abstract}

Total hip arthroplasty (THA) is a common technique for the surgical management of degenerative hip disease and has been called the operation of the century [1]. Over 7.2 million Americans are currently living with a hip or knee arthroplasty

One or more of the authors of this paper have disclosed potential or pertinent conflicts of interest, which may include receipt of payment, either direct or indirect, institutional support, or association with an entity in the biomedical field which may be perceived to have potential conflict of interest with this work. For full disclosure statements refer to https://doi.org/10.1016/j.arth.2019.04.014.

* Reprint requests: Roger Erivan, MD, Orthopedic and Trauma Surgery Department, Hôpital Gabriel Montpied, CHU de Clermont Ferrand BP 69, 63003 Clermont Ferrand, France. implant [2]. Satisfaction mainly depends on the patient's expectations [3]. Because of the increasing number of patients and the variety of prostheses and fixation modalities available for the surgeon, evaluation of patients with a painful arthroplasty implant can be very difficult. The growing number of patients who undergo multiple revision surgeries further complicates evaluation of painful implants [4]. Identifying the source of pain is paramount for determining appropriate treatment and ensuring successful outcome in terms of the management and relief of pain $[4,5]$. A painful prosthesis can lead to economic problems when revision is needed [6], but fortunately this does not concern all patients. 
The difficulty is that each surgeon has his or her own way of seeing the problem, and there is no consensus for the evaluation of these patients. It is often difficult to assess a patient who was promised to be pain free after surgery but is not. Although reasons for prosthesis replacement are well known and fully described [7] and the reasons for painful prosthesis are also well known [8-10], there have been no studies of the distribution of surgical and nonsurgical causes of painful prosthesis in daily practice.

The present study concerns the evaluation of unexplained painful THA and provides clinical results after application of a decision tree for painful THA.

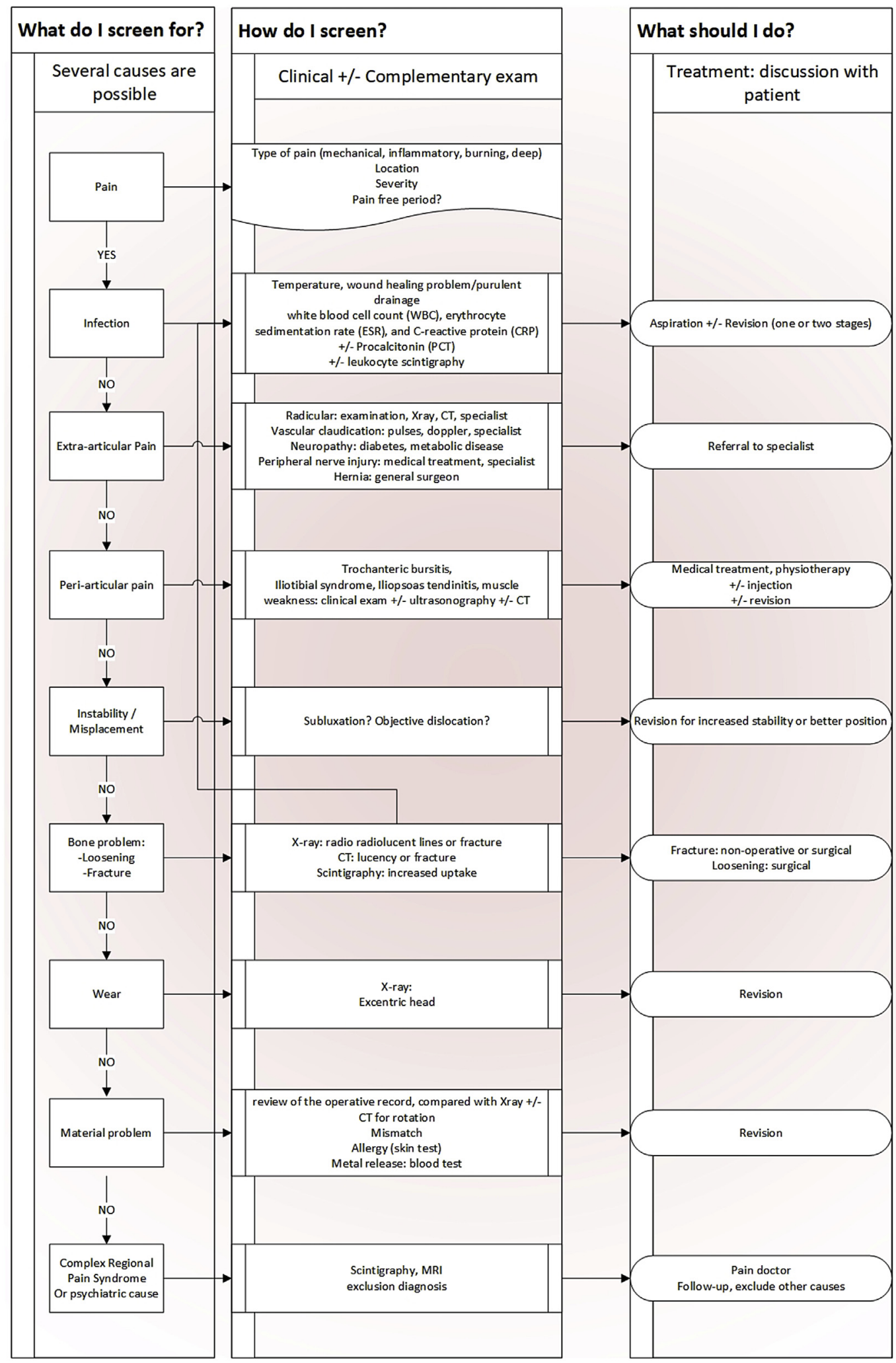

Fig. 1. Decision tree for painful hip arthroplasty. CT, computed tomography; MRI, magnetic resonance imaging. 
The study hypothesis was that it is possible to find the cause of the pain in most cases.

\section{Material and Methods}

A single-center retrospective study reviewed all 1130 consultations held between April 1, 2017 and July 31, 2018. All patients consulting for unexplained painful hip arthroplasty were included. Patients with pain with known cause, such as dislocation, fracture, or infection, were excluded, as were cases of painful prosthesis in the 6 first months after the last surgery.

Patients were characterized in terms of side, gender, and body mass index (BMI). Previous operative reports were analyzed for etiology of the first prosthesis, date of surgery, revisions, and reasons. Data further included whether the hip had been operated on by another surgeon, the date of the clinical review, and pain characteristics: type, daily variation and intensity of pain, and pain-free periods. Mobility, ability to walk, and Devane activity level were assessed.

All hips followed the decision tree shown in Figure 1 to assess the cause of the pain. This decision tree was based on Lanting's research [11].

Final diagnoses and any revision after diagnosis were recorded.

Patient demographics were then analyzed according to cause.

The primary endpoint was the final diagnosis. Secondary endpoints were to find a patient characteristic that could explain a cause for the pain with subgroup comparison between main causes and assessment of risk factors. We also compared the cause based on the primary and revision surgery.

Statistics were computed with Excel 2017 (Microsoft, Redmond, WA). Results were expressed as numbers and percentage for categorical data and as mean \pm standard deviation (range) for continuous data. Quantitative variables were compared between groups using Student t-test for continuous variables. Analysis of variance for qualitative or categorical data used chi-square test (or Fisher's exact test when this was not possible according to the 1954 Cochran Criterion that all classes must have a theoretical nonzero value and that $80 \%$ of classes must have theoretical values $\geq 5$ ). There were no missing data, and all hips were analyzed. The significance threshold was set at $P<.05$.

\section{Results}

Of the 1130 consultations reviewed, 384 had a painful hip or knee arthroplasty, 313 had an unexplained painful knee or hip prosthesis, and 201 hips in 194 patients were included as unexplained painful hip arthroplasty 6 months postoperatively. The 71 painful hip and knees excluded were 47 hips with known cause including 12 dislocations, 2 fractures, 11 infection, and 21 with less than 6 months of follow-up. Ninety-three hips (46.3\%) were right sided. One hundred twenty-two hips (60.7\%) were in female hips. Mean BMI was $30.0 \pm 6.0$ (15.3 to 49.7 ).

The main etiology for the prosthesis was osteoarthritis, in 159 hips (79.1\%); other etiologies comprised dysplasia in 16 hips (8.0\%), acute fracture in $5(2.5 \%)$, necrosis in $8(4.0 \%)$, trauma in $5(2.5 \%)$, and inflammation in $8(4.0 \%)$. Mean age at primary surgery was $56.5 \pm 13.9$ years ( 19.4 to 87.9 ), and mean age at last surgery was $60.6 \pm 11.7$ years ( 34.4 to 87.9 ). The painful prosthesis was primary arthroplasty in 142 hips (70.6\%) and revision arthroplasty in 59 hips (29.4\%). Forty of the revision hips (67.8\%) had 1 revision prior to the clinical evaluation, 9 (15.3\%) had 2, $5(8.5 \%)$ had 3, $1(1.7 \%)$ had 4, 3 (5.1\%) had 5 , and $1(1.7 \%)$ had 9 . The cause of the last revision was infection in 4 hips (6.8\%), loosening in 25 (42.4\%), dislocation in 13 (22.0\%), head-liner exchange for polyethylene wear in 12 (20.3\%), and other in 5 (8.5\%) (2 fractures, 1 abductor fixation, 1 iliopsoas 
Table 2

Qualitative Variables According to Frequent Causes of Painful Hip Arthroplasty on Analysis of Variance (Chi-Square Test or Fisher's Exact Test, as Appropriate).

\begin{tabular}{|c|c|c|c|c|c|c|c|c|c|c|c|c|}
\hline $\begin{array}{l}\text { Final } \\
\text { Diagnosis }\end{array}$ & Side & Gender & $\begin{array}{l}\text { Etiology } \\
\text { of First } \\
\text { Prosthesis }\end{array}$ & $\begin{array}{l}\text { Type of } \\
\text { Pain }\end{array}$ & $\begin{array}{l}\text { Daily } \\
\text { Variation }\end{array}$ & $\begin{array}{l}\text { Pain Same as } \\
\text { Preop }\end{array}$ & $\begin{array}{l}\text { Pain } \\
\text { Level }\end{array}$ & $\begin{array}{l}\text { Pain- } \\
\text { Free } \\
\text { Period }\end{array}$ & $\begin{array}{l}\text { Managed } \\
\text { in Our } \\
\text { Center }\end{array}$ & Mobility & Walking & $\begin{array}{l}\text { Devane } \\
\text { Activity } \\
\text { Level }\end{array}$ \\
\hline None & 0.998 & 0.993 & 0.929 & 0.994 & 0.961 & 0.985 & 0.480 & 0.993 & 0.997 & 0.992 & 0.929 & 0.797 \\
\hline Infection & 1.000 & 0.998 & 0.995 & 0.991 & 0.956 & 0.998 & 0.874 & 0.992 & 0.977 & 0.963 & 0.757 & 0.571 \\
\hline Loosening & 0.554 & 0.583 & 0.983 & 0.014 & 4.43E-03 & 0.990 & 0.074 & 0.423 & 0.906 & 0.994 & 0.575 & 0.589 \\
\hline Wear & 0.593 & $\begin{array}{l}2.01 E- \\
04\end{array}$ & 0.912 & 0.009 & 0.831 & 0.984 & 0.938 & 0.004 & 0.962 & 0.986 & 0.898 & 0.808 \\
\hline $\begin{array}{l}\text { Periarticular } \\
\text { pain }\end{array}$ & 0.426 & 0.056 & 0.953 & $\begin{array}{l}\text { 3.89E- } \\
05\end{array}$ & 0.027 & 0.988 & 0.018 & 0.607 & 0.949 & 0.967 & 0.890 & 0.738 \\
\hline $\begin{array}{l}\text { Material } \\
\text { problem }\end{array}$ & 0.564 & 0.724 & 0.932 & 0.567 & 3.83E-05 & 0.979 & 0.166 & 0.980 & 0.953 & 0.982 & 0.208 & 0.759 \\
\hline $\begin{array}{l}\text { Projected } \\
\text { pain }\end{array}$ & 0.662 & 0.273 & 0.963 & 0.006 & 0.058 & 0.981 & 0.003 & 0.678 & 0.978 & 0.996 & 0.996 & 0.964 \\
\hline
\end{tabular}

Bolded values represents the $P$-value $<.05$.

section, 1 metalosis). The mean interval between last surgery and clinical review was $113.7 \pm 83.2$ months (6.1 to 325.8).

Final diagnoses comprised the following findings:

- periarticular pain in 53 (26.4\%): 40 cases of trochanteric bursitis, 5 of iliopsoas tendinitis, 5 of abductor deficiency, 1 of ischial tuberosity tendinitis, and 2 of heterotopic ossification;

- projected pain in 49 (24.4\%): 45 cases of back pain with or without neuropathy, 3 of knee osteoarthritis, and 1 of metabolic neuropathy;

- wear in 40 (19.9\%), in the polyethylene liner;

- loosening in 20 (10.0\%): 8 of the femoral component and 12 of the cup;

- material problems in 17 (8.5\%): 13 of trunnionosis and 4 of metallosis in metal-on-metal implants;

- no diagnosis in 7 hips (3.5\%);

- infection in 6 (3.0\%), all chronic;

- instability without real dislocation in 3 (1.5\%);

- misplacement in 3 (1.5\%), all for leg-length discrepancy;

- fracture in 2 (1.0\%): 1 greater trochanter and 1 ilio-ischiopubic ramus;

- complex regional pain syndrome in $1(0.5 \%)$.

One hundred thirty-eight hips (68.7\%) underwent no revision after diagnosis, 63 (31.3\%) underwent revision: 55 (27.4\%) in our center and 8 (3.9\%) elsewhere. Revision procedures were performed at a mean $159.3 \pm 91.2$ months (8.8 to 326.3 ) after the last surgery.
Types of pain comprised burning in 83 hips (41.3\%), sharp in 12 (6.0\%) and deep in 106 (52.7\%). Daily variation was mechanical in 127 hips (63.2\%), inflammatory in 9 (4.5\%), and pain was constant in $65(32.3 \%)$. The pain was the same as the preoperative pain in 9 hips (4.0\%) and different in 192 hips (95.5\%). In 104 hips (51.7\%), pain level was low (visual analog scale [VAS] from 1 to 3), in 86 (42.8\%) moderate (VAS 4 to 6 ), and in 11 (5.5\%) high (VAS 7 to 9 ); there were no hips of very high pain level (VAS 10$)$. Thirty-seven (18.4\%) hips had no pain-free period after last surgery, and 164 (81.6\%) had a pain-free period, at a mean $9.3 \pm 6.5$ years (1.0 to 28.0). Mean hip and osteoarthritis outcome score (HOOS) score was 55.6 \pm 20.9 (0 to 100). Mean Medical Outcomes Study Short-Form General Health Survey (SF-12) Mental component was $55.7 \pm 8.9$ (27.4 to 71.9) and Physical component was $32.9 \pm 10.8$ (15.4 to 57.8 ).

One hundred thirty-seven hips (68.2\%) were originally operated on by our team, 3 (1.5\%) were referred by another surgeon, $2(1.0 \%)$ were referred by their general practitioner, and 59 (29.4\%) cases consulted spontaneously.

Flexion exceeded $90^{\circ}$ in 186 hips (92.5\%) and was between $70^{\circ}$ and $89^{\circ}$ in $12(6.0 \%)$ and between $50^{\circ}$ and $69^{\circ}$ in $3(1.5 \%)$. Walking was impossible in 1 case $(0.5 \%)$, required 2 crutches in 8 (4.0\%), 2 canes in 2 (1.0\%), one permanent cane in 26 (12.9\%), a cane most of the time in 56 (27.9\%), a cane for long walks or episodes of lameness in 97 (48.3\%), and no assistance (normal walking) in 11 (5.5\%). Devane activity level was 1 in 3 hips (1.5\%), 2 in 63 (31.3\%), 3 in 92 (45.8\%), 4 in 37 (18.4\%), and 5 in $6(3.0 \%)$.

Table 3

Clinical Scores According to Frequent Causes of Painful Hip Arthroplasty.

\begin{tabular}{|c|c|c|c|c|c|c|c|}
\hline Diagnosis & Number of Hips & HOOS & $P$ & SF-12 Mental & $P$ & SF-12 Physical & $P$ \\
\hline \multicolumn{8}{|l|}{ None } \\
\hline Yes & 7 & $33.1 \pm 19.1$ & \multirow[t]{2}{*}{.003} & $45.2 \pm 12.4$ & \multirow[t]{2}{*}{0.001} & $30.0 \pm 8.2$ & \multirow[t]{2}{*}{0.483} \\
\hline No & 194 & $56.4 \pm 20.5$ & & $56.1 \pm 8.6$ & & $33.0 \pm 10.9$ & \\
\hline \multicolumn{8}{|l|}{ Infection } \\
\hline Yes & 6 & $44.0 \pm 26.1$ & \multirow[t]{2}{*}{.169} & $54.0 \pm 11.4$ & \multirow[t]{2}{*}{0.641} & $29.6 \pm 5.8$ & \multirow[t]{2}{*}{0.459} \\
\hline No & 195 & $55.9 \pm 20.7$ & & $55.7 \pm 8.9$ & & $33.0 \pm 11.0$ & \\
\hline \multicolumn{8}{|l|}{ Loosening } \\
\hline Yes & 20 & $43.3 \pm 16.7$ & \multirow[t]{2}{*}{.009} & $53.0 \pm 11.1$ & \multirow[t]{2}{*}{0.161} & $28.0 \pm 7.7$ & \multirow[t]{2}{*}{0.040} \\
\hline No & 181 & $56.8 \pm 20.9$ & & $56.0 \pm 8.6$ & & $33.4 \pm 11.0$ & \\
\hline \multicolumn{8}{|l|}{ Wear } \\
\hline Yes & 40 & $62.2 \pm 17.8$ & \multirow[t]{2}{*}{.029} & $58.2 \pm 6.8$ & \multirow[t]{2}{*}{0.054836} & $34.0 \pm 11.4$ & \multirow[t]{2}{*}{0.464922} \\
\hline No & 161 & $53.9 \pm 21.3$ & & $55.1 \pm 9.3$ & & $32.6 \pm 10.7$ & \\
\hline \multicolumn{8}{|c|}{ Periarticular pain } \\
\hline Yes & 53 & $62.0 \pm 22.6$ & \multirow[t]{2}{*}{.011} & $56.7 \pm 7.6$ & \multirow[t]{2}{*}{0.3396} & $35.1 \pm 12.0$ & \multirow[t]{2}{*}{0.0869} \\
\hline No & 148 & $53.3 \pm 19.8$ & & $55.3 \pm 9.3$ & & $32.1 \pm 10.3$ & \\
\hline \multicolumn{8}{|c|}{ Material problem } \\
\hline Yes & 17 & $51.0 \pm 22.9$ & \multirow[t]{2}{*}{.349} & $57.6 \pm 8.0$ & \multirow[t]{2}{*}{0.363} & $32.6 \pm 9.5$ & \multirow[t]{2}{*}{0.928} \\
\hline No & 184 & $56.0 \pm 20.7$ & & $55.5 \pm 9.0$ & & $32.0 \pm 11.0$ & \\
\hline \multicolumn{8}{|c|}{ Projected pain } \\
\hline Yes & 49 & $55.6 \pm 18.1$ & \multirow[t]{2}{*}{.993} & $54.1 \pm 9.2$ & \multirow[t]{2}{*}{0.172} & $33.8 \pm 11.1$ & \multirow[t]{2}{*}{0.506} \\
\hline No & 152 & $55.6 \pm 21.8$ & & $56.2 \pm 8.8$ & & $32.6 \pm 10.8$ & \\
\hline
\end{tabular}

Bolded values represents the $P$-value $<.05$. 


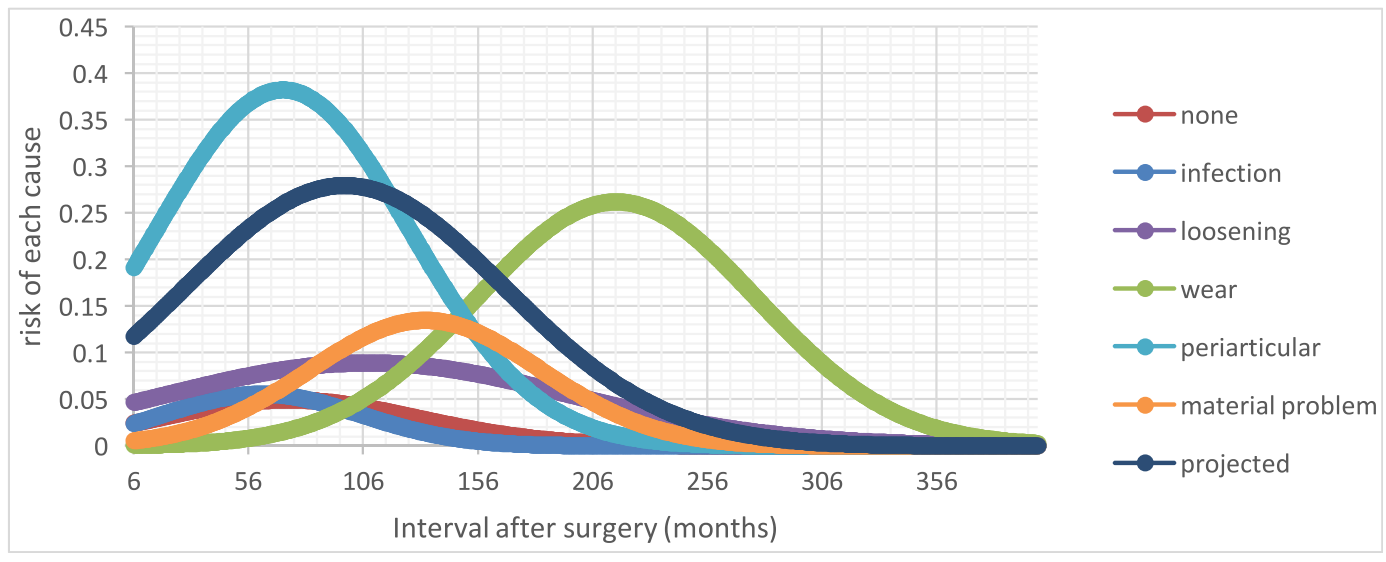

Fig. 2. Emergence of each frequent cause of painful hip arthroplasty.

Subgroup analysis per cause distinguished 7 subgroups. Comparisons concerned rates of established diagnosis, infection, loosening, wear, periarticular pain, material problems, and projected pain; the other subgroups were not compared because of low numbers, preventing representativeness and meaningful statistical analysis. Continuous and discrete variables are compared in Table 1; Table 2 presents qualitative variables significantly associated with painful hip arthroplasty on analysis of variance.

Table 3 presents clinical scores according to cause.

The main result of subgroup analysis (Tables 1 and 2) was that hips without diagnosis were younger at first and last surgery and had lower HOOS and SF-12 mental scores. Hips with infection had higher BMI. Hips with loosening more frequently had deep or constant pain and less frequently burning or mechanical pain, and had lower HOOS and SF-12 physical scores. Hips with wear were younger at first and last surgery and had longer intervals between surgeries. They more often had a pain-free period, which moreover was longer. They were more often males. Their pain was deeper and less burn like. They had higher HOOS scores. Hips with periarticular pain were older at first surgery, had fewer prior revision procedures, and had shorter intervals between last surgery and study assessment. Their pain was more often burning and less often deep; daily variation was more often mechanical and less often inflammatory in origin or with constant pain. Pain level was higher. HOOS scores were higher. Hips with material problems more had constant pain and less often mechanical pain. Hips with projected pain were older at last surgery and had shorter pain-free periods after surgery. The type of pain was more often sharp, and pain level was lower.

Figure 2 shows onset time for the various causes, shedding light on which causes may be found at what interval, and in what proportion compared to the other causes. It shows that early pain is more likely to be periarticular, medium-term pain more likely to be projected, and late pain more likely to be related to wear. Nevertheless, each cause can obviously be found and must be sought at any time point.

Table 4 present the comparison between primary and revision surgery. We found no difference for patients' characteristics between primary and revision groups except for the age at first surgery with younger patients in revision group. HOOS and SF-12 mental scores were lower in revision group. We did not find a significant difference in final diagnosis found.

\section{Discussion}

The main result is that a diagnosis and a cause of pain in the hip can be determined in the majority of cases, as the present study had $3.5 \%$ of cases for which a diagnosis was not able to be determined.
Our hypothesis is confirmed. One quarter of hips had projected pain, another quarter had periarticular pain. Ten percent had loosening ( $6 \%$ of the cup, $4 \%$ of the femoral component); $8.5 \%$ had material problems; and other causes were rarer. The study showed the importance of clinical examination to avoid overlooking an extra-articular cause, which concerned more than half of the hips. The graph of the time of onset of each cause could help surgeons to focus more on certain causes, but it is important to consider all causes at any time. Hips, moreover, may show several causes. The take-home message is to avoid preconceived diagnosis: it is important to perform extensive exploration of the pain.

The present findings are supported by previous studies highlighting the importance of back problems, which worsen the results of THA and lead to poor results [12,13]. Periarticular pain is poorly described: the best described is iliopsoas impingement, because of its surgical treatment $[14,15]$, but we found no studies of prevalence. Loosening is not the most common cause of painful THA, whereas it is the most common cause of revision; however, it represented only $10 \%$ of painful prostheses in the present series, so the other causes have to be borne in mind.

Analysis of secondary endpoints may suggest risk factors for each cause; however, the study was not designed with this as a

Table 4

Comparison Between Primary and Revision Surgery.

\begin{tabular}{|c|c|c|c|}
\hline Parameter & Primary Surgery & Revision Surgery & $P$ \\
\hline Number of Patients & 142 & 59 & - \\
\hline Age at first surgery & $60.0 \pm 11.5$ & $48.0 \pm 15.6$ & 7.85E-09 \\
\hline Female & $84 ; 59.15 \%$ & $38 ; 64.41 \%$ & .488 \\
\hline Right side & $66 ; 46.48 \%$ & $27 ; 45.76 \%$ & .926 \\
\hline \multicolumn{4}{|l|}{ Diagnosis found } \\
\hline None & $4 ; 2.82 \%$ & $5 ; 8.47 \%$ & \multirow[t]{7}{*}{.396} \\
\hline Infection & $4 ; 2.82 \%$ & $2 ; 3.39 \%$ & \\
\hline Loosening & $16 ; 11.27 \%$ & $4 ; 6.78 \%$ & \\
\hline Wear & $27 ; 19.01 \%$ & $13 ; 22.03 \%$ & \\
\hline Periarticular pain & $42 ; 29.58 \%$ & $11 ; 18.64 \%$ & \\
\hline Material problem & $13 ; 9.15 \%$ & $4 ; 6.78 \%$ & \\
\hline Projected pain & $34 ; 23.94 \%$ & $15 ; 25.42 \%$ & \\
\hline BMI & $30.0 \pm 5.9$ & $30.1 \pm 6.3$ & .990 \\
\hline $\begin{array}{l}\text { Number of prior } \\
\text { revision }\end{array}$ & 0 & $1.7 \pm 1.4$ & - \\
\hline $\begin{array}{l}\text { Interval after last } \\
\text { surgery (mo) }\end{array}$ & $121.0 \pm 84.8$ & $96.1 \pm 77.2$ & .054 \\
\hline Pain-free period (y) & $9.4 \pm 6.5$ & $9 \pm 6.5$ & .676 \\
\hline HOOS & $57.8 \pm 20.7$ & $50.2 \pm 20.6$ & .023 \\
\hline SF-12 mental & $57.3 \pm 7.5$ & $51.9 \pm 10.8$ & 1.23E-04 \\
\hline SF-12 physical & $33.8 \pm 11.2$ & $30.5 \pm 9.6$ & .057 \\
\hline
\end{tabular}

Bolded values represents the $P$-value $<.05$. 
main objective, and the results are no more than suggestive. Hip without diagnosis were younger. Unexplained painful hip arthroplasty is poorly studied, but some authors suggest means of identifying the cause [16]; even after extensive research, however, no cause could be identified in $3.5 \%$ of the present hips. Hips arthroplasties with infection had higher BMI; this has been well described and is in agreement with the literature $[13,17,18]$. Hips with implant wear were young, male, and with longer pain-free periods. A longer pain-free period is logical: by definition, a hip with wear was pain free before onset of pain. The high rate of severe wear in young patients is also well reported [19]. Hips with periarticular pain were older at first surgery, had fewer prior revision procedures, and their pain level was higher. One explanation could be that these patients have less tolerance for pain because they had higher clinical scores, but it must be borne in mind that there might be another cause for what we call tendinitis. Ten years ago, if a patient presented with trunnionosis $[20,21]$, it would probably have been called trochanteric bursitis as we did not know what it was. Hips with projected pain were older at last surgery and had shorter pain-free periods after surgery. Most of these projected pains were in the back, and, although the incidence of low back pain should be lower after 65 years of age [22], this is not what we found. This raises the question of changing the pelvic position after THA [23]. The repartition of diagnosis found in primary and revision group seems similar in our study but the small size of each group can explain the lack of difference.

There are several limitations in the present study that might affect the results. One was that the design was retrospective; however, we included all consecutive cases meting the inclusion criteria and were able to include quite a large number of hips. In addition, there were few missing data. The diagnostic decision tree may be a second limitation and would need specific evaluation of its reproducibility and precision. A further point is that the study is only descriptive and did not have a control group which could have helped to better assess patient characteristics. A given patient can show several causes or be borderline between 2 causes. For example, a hip can have a both cup misplacement and iliopsoas tendinitis; in this particular case, the case would be considered as tendinitis if there was less than $10^{\circ}$ overhang and misplacement if not. Analysis of surgical approach, type of implant, implant alignment, and postoperative care could have found other risk factors, but these points were not studied here.

\section{Conclusion}

To our knowledge, this is the first study on the causes of painful hip arthroplasty in clinical practice, whether leading to revision or not. A systematic approach is needed to find the cause of the pain: physical examination, radiographic assessment, and laboratory studies. It is important to understand the pain so that it can be treated appropriately. Revision surgery can sometimes help-but the worst thing is to make the patient worse.

\section{Acknowledgments}

The authors thank the SOFCOT (Société Française de Chirurgie Orthopédique et Ttraumatologique) for participating for the fellowship of R.E. with W.P.

\section{References}

[1] Learmonth ID, Young C, Rorabeck C. The operation of the century: total hip replacement. Lancet 2007;370:1508-19. https://doi.org/10.1016/S01406736(07)60457-7.

[2] Maradit Kremers H, Larson DR, Crowson CS, Kremers WK, Washington RE, Steiner CA, et al. Prevalence of total hip and knee replacement in the United States. J Bone Joint Surg Am 2015;97:1386-97. https://doi.org/10.2106/ JBJS.N.01141.

[3] Suda AJ, Seeger JB, Bitsch RG, Krueger M, Clarius M. Are patients' expectations of hip and knee arthroplasty fulfilled? A prospective study of 130 patients. Orthopedics 2010;33:76-80. https://doi.org/10.3928/01477447-2010010407.

[4] Evans BG, Cuckler JM. Evaluation of the painful total hip arthroplasty. Orthop Clin North Am 1992;23:303-11.

[5] Blum A, Raymond A, Teixeira P. Strategy and optimization of diagnostic imaging in painful hip in adults. Orthop Traumatol Surg Res 2015;101:S85-99. https://doi.org/10.1016/j.otsr.2014.11.002.

[6] Bozic KJ, Kamath AF, Ong K, Lau E, Kurtz S, Chan V, et al. Comparative epidemiology of revision arthroplasty: failed THA poses greater clinical and economic burdens than failed TKA. Clin Orthop 2015;473:2131-8. https:// doi.org/10.1007/s11999-014-4078-8.

[7] Ulrich SD, Seyler TM, Bennett D, Delanois RE, Saleh KJ, Thongtrangan I, et al. Total hip arthroplasties: what are the reasons for revision? Int Orthop 2008;32:597-604. https://doi.org/10.1007/s00264-007-0364-3.

[8] Piscitelli P, Iolascon G, Innocenti M, Civinini R, Rubinacci A, Muratore M, et al. Painful prosthesis: approaching the patient with persistent pain following total hip and knee arthroplasty. Clin Cases Miner Bone Metab 2013;10: 97-110.

[9] Lam YF, Chan PK, Fu H, Yan CH, Chiu KY. A review of the clinical approach to persistent pain following total hip replacement. Hong Kong Med J 2016;22: 600-7. https://doi.org/10.12809/hkmj164969.

[10] Vaz S, Ferreira TC, Salgado L, Paycha F. Bone scan usefulness in patients with painful hip or knee prosthesis: 10 situations that can cause pain, other than loosening and infection. Eur J Orthop Surg Traumatol 2017;27:147-56. https://doi.org/10.1007/s00590-016-1884-6.

[11] Lanting BA, MacDonald SJ. The painful total hip replacement: diagnosis and deliverance. Bone Joint J 2013;95-B:70-3. https://doi.org/10.1302/0301620X.95B11.32948.

[12] Eneqvist T, Nemes S, Brisby H, Fritzell P, Garellick G, Rolfson O. Lumbar surgery prior to total hip arthroplasty is associated with worse patient-reported outcomes. Bone Joint J 2017;99-B:759-65. https://doi.org/10.1302/0301620X.99B6.BJJ-2016-0577.R2.

[13] Loth FL, Giesinger JM, Giesinger K, MacDonald DJ, Simpson AHRW, Howie CR, et al. Impact of comorbidities on outcome after total hip arthroplasty. J Arthroplasty 2017;32:2755-61. https://doi.org/10.1016/j.arth.2017.04.013.

[14] Benad K, Delay C, Putman S, Girard J, Pasquier G, Migaud H. Technique to treat iliopsoas irritation after total hip replacement: thickening of articular hip capsule through an abridged direct anterior approach. Orthop Traumatol Surg Res 2015;101:973-6. https://doi.org/10.1016/j.otsr.2015.06.024.

[15] Morohashi I, Homma Y, Kanda A, Yamamoto Y, Obata H, Mogami A, et al. Iliopsoas impingement after revision total hip arthroplasty treated with iliopsoas muscle transection. Ann Med Surg 2016;7:30-3. https://doi.org/ 10.1016/j.amsu.2016.03.004.

[16] Cuckler JM. Unexplained pain after THR: what should i do? Orthopedics 2010;33:648. https://doi.org/10.3928/01477447-20100722-28.

[17] DeMik DE, Bedard NA, Dowdle SB, Elkins JM, Brown TS, Gao Y, et al. Complications and obesity in arthroplasty-A hip is not a knee. J Arthroplasty 2018;33:3281-7. https://doi.org/10.1016/j.arth.2018.02.073.

[18] Bookman JS, Schwarzkopf R, Rathod P, Iorio R, Deshmukh AJ. Obesity: the modifiable risk factor in total joint arthroplasty. Orthop Clin North Am 2018;49:291-6. https://doi.org/10.1016/j.ocl.2018.02.002.

[19] Sonohata M, Kitajima M, Kawano S, Mawatari M. Wear of XLPE liner against zirconium heads in cementless total hip arthroplasty for patients under 40 years of age. Hip Int 2017;27:532-6. https://doi.org/10.5301/hipint.5000513.

[20] Cooper HJ, Della Valle CJ, Berger RA, Tetreault M, Paprosky WG, Sporer SM, et al. Corrosion at the head-neck taper as a cause for adverse local tissue reactions after total hip arthroplasty. J Bone Joint Surg Am 2012;94:1655-61.

[21] Lachiewicz PF, O’Dell JA. Trunnion corrosion in metal-on-polyethylene hip arthroplasty. Bone Joint J 2018;100-B:898-902. https://doi.org/10.1302/ 0301-620X.100B7.BJJ-2017-1127.R2.

[22] Hoy D, Brooks P, Blyth F, Buchbinder R. The Epidemiology of low back pain. Best Pract Res Clin Rheumatol 2010;24:769-81. https://doi.org/10.1016/ j.berh.2010.10.002

[23] Komiyama K, Hamai S, Hara D, Ikebe S, Higaki H, Yoshimoto K, et al. Dynamic hip kinematics during squatting before and after total hip arthroplasty. J Orthop Surg 2018;13:162. https://doi.org/10.1186/s13018-018-0873-3. 